\title{
WILL I SURVIVE? THE ROLE OF PERCEIVED RISK AND KNOWLEDGE TOWARD HOPE IN THE TIME OF PANDEMIC: STUDY ON INDONESIAN STUDENTS
}

\author{
Gumgum Gumelar $^{1^{*}}$, Herdiyan Maulana ${ }^{2}$, Gita Irianda Rizkyani Medellu ${ }^{3}$ \\ $1^{* * 2,3}$ Faculty of Psychology, Universitas Negeri Jakarta, Indonesia. \\ Email: ${ }^{1 *}$ ggumelar@unj.ac.id, ${ }^{2}$ herdiyan-maulana@unj.ac.id, ${ }^{3}$ gitairianda@unj.ac.id \\ Article History: Received on $15^{\text {th }}$ July 2020, Revised on $28^{\text {th }}$ February 2021, Published on $2^{\text {nd }}$ March 2021
}

\begin{abstract}
Purpose of the study: The purpose of this study was to examine participant's hopes whether the pandemic will end based on the perception of risk concerning vulnerability, severity, and anxiety as well as their knowledge about the pandemic among university students in Indonesia.

Methodology: $431(20 \%$ male and $80 \%$ female; Age mean $=19.98 ; \mathrm{SD}=1.421)$ undergraduate students in psychology were recruited from across university in Indonesia. A battery scale consists of three questionnaires evaluating perceived risk, knowledge, and hope were administered using the online survey. A multiple regression analysis was applied to examine the hypotheses.

Main Findings: The results demonstrated that perceived risk and knowledge emerge as significant predictors of hope. The results also showed that there was a negative relationship between the dimension of perceived risk and hope. There was no significant correlation between health knowledge and hope. The results indicated a statistically significant model of regression. However, this study revealed that there was no statistically significant difference between health knowledge and hope.
\end{abstract}

Applications of this study: The psychological aspect of risk perception and knowledge could be acknowledged as important variables to enhance the hope of university students to face this pandemic.

Novelty/Originality of this study: The study offers a further explanation about the scope of earlier research in the field of hope in pandemic -19. It also provides a new research paradigm to the area of perceived risk by introducing understudied individual factors, such as knowledge associated with the hope of facing the pandemic among college students.

Keywords: Covid-19, Perceived Risk, Hope, Knowledge, Vulnerability, Severity, Anxiety, College Students.

\section{INTRODUCTION}

After the first breakout of a novel coronavirus (-19) in Wuhan, China, at the end of 2019, the Virus rapidly spread worldwide. While many countries experienced a first pandemic wave at the end of 2019, Indonesia was initially affected by imported cases followed by an acceleration of cases mainly due to travellers in March 2020. The government begins to pay more serious attention to the Virus once the first two patients were confirmed and officially announced by Indonesia's president, Joko Widodo, in a press conference on March, $2^{\text {nd }} 2020$.

The pandemic not only carries the risk of death from a viral infection but also does have psychological pressure on people in China and the rest of the world (Duan \& Zhu, 2020). In Indonesia, the announcement of the first case in early March is likely to lead a severe pressure on all levels of society. The spread of the Virus forces local authorities to implement strict social isolation and to regulate lock-down across social facilities (schools, worship places, and universities). The ministry of education develops an alternative method of learning so the students can learn from their homes. The program is known as "Belajar di Rumah" (school from home) and has been initiated throughout the country. Aside from being its educational purpose, the program was expected to maintain a student's mental health during the social quarantine.

There are emerging studies about the psychological impact of the epidemic across population groups, e.g., -19 patients, medical staff, children, and older adults (Q. Chen et al., 2020); (Li et al., 2020); (Yang et al., 2020). However, there has been little attention to the mental health study focusing on students during the pandemic (Cao et al., 2020), in particular to the Indonesian student facing the negative impact of the pandemic.

There are individual differences in reacting to threats of the pandemic. Reactions can range from fear to ignorance (Wheaton et al., 2012). At the end of the spectrum, some people ignore or deny that the risks are real, and fail to engage in recommended health behaviors such as hygiene practices and social distance. Many people react with intense anxiety or fear. A moderate level of fear or anxiety can motivate people to overcome health threats, but severe stress can be debilitating (Taylor, 2019).

It is essential to understand how people managed their future goals once the pandemic of -19 is over. Knowing when the pandemic is over would likely enhance their psychological well-being. Several questions immediately come to mind when such an assumption is put forward. For example, individuals begin to articulate their future after the -19 Pandemic 
ends; how far into the future does this articulation extend; what are the important and essential aspects of this future after -19 Pandemic.

People are more comfortable and mentally well if they are in a predictable situation. As consequence, people would always tend to predict what will happen in the future. This prediction may lead them to different routes of life scenarios, whether they are leading to favorable or unfavorable life outcomes. People's expectation of favorable life outcomes is known as hope. Hope to define as the perceived ability to get the path to the desired goal, and motivate yourself through the agency thinking to use that pathway (Snyder, 2002). Hope is not emotions but dynamic cognitive, motivational systems (Snyder et al., 1991). In this sense, emotions follow the cognition in the process of pursuing goals $\underline{\text { (Snyder, }}$ 2002). Expectations can be measured in a cross-situational condition that correlates positively with self-esteem, perceived problem-solving abilities, perception of control, optimism, positive effectiveness, and positive outcome expectations (Snyder et al., 1991).

Differences in behavioral responses to health among students occur because of an individual's ability to identify factors that influence health outcomes and compliance in treatment (Kalichman et al., 2008) This has also been linked to the inability to achieve suppression from the spread of viruses, such as HIV (Jones et al., 2013) ; (Ownby et al., 2013). This factor, commonly called health literacy, depends on how humans perceive these risks to health. Health literacy also influences how they see that health or health problems through the perception of risk they receive. Risk perception is a subjective assessment that has been carried out by people about the characteristics and severity of risks. This concept is most commonly used to refer to natural hazards and threats to the environment or health, such as nuclear power. Risk perception often targets in health behavior change interventions, and recent meta-analytic evidence suggests that successful interventions that involve and change risk perceptions result in further improvements in health behavior (Ferrer \& Klein, 2015). Risk perception can be minimized or even appropriately managed if the individual has a high health literacy. Health literacy defines as "the extent to which individuals can obtain, process, and understand basic health information and services needed to make the right health decisions" (Bish et al., 2011; Selden et al., 2000).

By investigating the perceptions of risks that can affect health knowledge, this current research could expand the research scope on health behavior. Specifically in handling the spread of viruses, and support health knowledge and risk perception variables on the spread of coronaviruses, and increase understanding of the importance of healthy living for college students.

\section{LITERATURE REVIEW}

\section{Hope}

Snyder et al., (1991) indicate that the expectations have surpassed wishful thinking into an understanding of how deliberate thinking leads to adaptive action (Snyder et al., 1991) They identified hope as the human capacity to; (a) conceptualize their goals in a more precise way (goal thinking), (b) develop strategies to achieve these goals (pathways thinking), and (c) initiate and maintain motivation for using the respective strategy (agency thinking). Everyone may have the ability to think purposively, but it is often not intentional. Agency pathways and thinking are both needed for embracing hope; however, they are not sufficient to sustain a successful pursuit of goals. Thus, agency pathways and thought are additive, reciprocal, and positively related, although they are not identical (Snyder et al., 1991). Both of these components need hopeful thinking. Hope reflects the relatively enduring cross-situational subjective judgments of abilities related to goals (Snyder, 2002).

Hope theory stated that hope is individuals' pathways and agency thinking, which relatively stable across time and targets. Snyder (2002) states that people carry their broad set of dispositions regarding expectations for the pursuit of their individual goals. Hope variables predict many important positive outcomes, from physical and mental health to academic and athletic success (Snyder, 2002). Research has shown that child's hopeful thinking is positively related to perceived competence and self-esteem (Marques et al., 2009) and negatively associated with depressive symptoms (Snyder et al., 1991). People with higher hope are likely to succeed in pursuing their goals. They also have a higher chance to experience more positive emotions. On the contrary, people with a lower level of hope tend to have more challange overcoming adversity and, therefore, might prone to more negative emotions (Lopez et al., 2004) (Snyder, 2002). Further, children and adolescents who report higher levels of hope also seen themselves more favorably and have a slightly positive self-referential image.

Previous studies have evidence showing that hope is related to one's life satisfaction and well-being (Gilman et al., 2006). In a similar study, (Marques et al., 2009) found that hope significantly and positively correlated with global life satisfaction and mental health for high school students. Higher levels of hope are also related to scholastic and social competencies (Onwuegbuzie \& Daley, 1999). Recent studies provide preliminary evidence for the efficacy of growing hope in different samples. As an example, adults who had previously completed a psychological intervention designed to increase hopeful thinking and increasing activity pursuit of goals are significantly having a higher level of hopes, goals in life, and self-esteem, as well as less symptoms of depression and anxiety (Cheavens et al., 2007). Based on the above explanations, hope could be summarised that that, as a strength, it would potentially help individual mental health from the adverse effects of unfavorable life events. 


\section{Perceived Risk}

Risk perceptions are may not solely define in the form of numeric information. Perceived risk needs to describe in a way people perceived their personal experiences on potential threats. For example, enforcement of preventive behavior results in a subsequent reduction of appropriate risk perception (Brewer et al., 2004), and engaging in risky behaviors is associated with appropriately higher risk perceptions (Mills et al., 2008). Moreover, risk perceptions are influenced by the information that we consider most important (Kahneman, 1973). For example, individuals would have a higher perceived risk of being infected by the disease when someone in their family diagnosed with the disease $\underline{(L}$. S. Chen \& Kaphingst, 2011). Although factors like family history might provide some relevant information about actual susceptibility to disease, other important information also plays a role in risk perception. For example, risk perceptions are often influenced by the frequency of a threat represented in media exposure (Slovic, 1987).

Contextual factors also influence risk perceptions. For example, as threats become more immediate, risk perceptions tend to become more pessimistic (Shepperd et al., 2000). Risk perceptions also tend to be higher when a health threat is difficult to control (Slovic, 1987). Moreover, effective contextual factors play a critical role; individuals that were experiencing anger tend to have more optimistic risk perceptions, whereas those who are experiencing fear tend to have more pessimistic risk perceptions (Lerner \& Keltner, 2000). General emotions can also influence the formation of risk perceptions. For example, distress is associated with higher risk perceptions (Mathur \& Levy, 2013), and depressed individuals may be more likely to adjust their risk perception estimates in response to health information than nondepressed individuals (Keller et al., 2002). These tendencies have important implications for the formation of risk perceptions in a health context, particularly given that many health threats and clinical care contexts evoke strong emotions (Ferrer \& Klein, 2015).

\section{Health Knowledge}

Health knowledge is a personal understanding of a particular health-related issue. A patient's knowledge about their specific health condition is vital in disease management. It is associated with positive health responses, such as in the medication and treatment adherence, the decision-making process, and might lead to better health outcomes (Grueninger, 1995). Studies have shown that patient with a chronic disease is likely to have lower knowledge of their condition (Barr et al., 2009; Volk et al., 2013). A previous study had identified reasons for disagreement on treatment between patients and providers showed that interventions that increase patients' knowledge of their disease might increase patient compliance regarding disease management (Hansen et al., 2015).

Research related to the spread of viruses and health knowledge has been conducted for research on HIV. HIV referred health knowledge is defined as having HIV-related information that would help with being aware of HIV risk behaviors, making informed decisions, and making behavioral changes if necessary (Carey \& .E.E. Schroder, 2002). Having a good health-related quality of life, adequate knowledge and understanding about disease conditions and how vulnerable one might be to these conditions is necessary, as this might lead to the behavioral changes required to achieve a healthy lifestyle of prevention and control of one's disease condition (Q. Wang et al., 2014). Although health knowledge is important, it alone is not sufficient to bring about behavioral change (Q. Wang et al., 2014).

\section{Relationships between Variable}

Researchers have identified the number of psychological factors that are positively associated with hope such as perceived risk and health knowledge/literacy. Hope is a crucial factor in the dynamic of living at risk. Psychological responses such as fear, fatalism, and misperception about the disease have been identified as personal factors that inhibit participation in cancer health promotion behaviors (Cardwell et al., 1993). Other studies in the field of breast cancer specifically identify the lack of knowledge about breast cancer as a significant obstacle to doing healthy behavi or Philips Other factors, such as confidence in the efficacy of disease prevention behavior, perceived threats and feelings of personal vulnerability, and methods of communicating cancer information, have also been cited as factors that influence health promotion behavior(Denniston, 1981).

The health belief model (HBM) should be used to explain people's behavior in responding to disease. (Rosenstock et al., 1994) developed this model and implemented preventive efforts related to health. HBM is one of the psychological approaches most often used to explain health-related behavior. Three essential factors in the Health Belief Model, are 1) Individual readiness to change behavior in avoiding a disease or minimize health risks. 2) There is a push in the individual environment that makes him change behavior.

Perceived risk, according to the health belief model, explains that perceived severity is a belief that a person has in connection with a feeling of the seriousness of a disease that can affect his current state of health. Someone evaluates how big the consequences arising from the disease, both medical outcomes such as death or disability and social impacts such as effects on work and life. It is important to take into account emotional and financial factors when considering the seriousness of the disease. The more consequences that are believed to occur as a result of the behavior of health risks to them, the higher the perception that the problem is a threat so that they will take action.

Perceived vulnerability is the perception of a perceived threat or vulnerability to the risks that will arise from the disease. Individuals vary in assessing these possibilities even though their health conditions are the same. The higher the 
perceived vulnerability, the greater the perceived threat, and the higher the likelihood of individuals to take action to overcome problems that might arise (Sarafino, 2008). individuals often ignore the possibility of themselves about threats to their illness, so it is not uncommon for individuals not to take action to overcome health problems that threaten them.

During the -19 pandemic, normal life patterns suddenly had to be changed immediately, and some people were confused about what, how, and should to do. Life pattern changes cause anxiety. Within normal limits, anxiety is a sign that is needed by individuals for a danger that is expecting to be better prepared. All of these things are creating a lot of concern for people leading to heightened levels of anxiety. Pandemics can lead to elevated levels of stress; Anxiety is a typical response to any stressful situation.

Each reaction contributed to the -19 Virus as a global event of anxiety through intensifying and amplifying the sense of urgency in the face of this new infectious disease. Many people have started to use health procedures in handling protection from viruses regularly, but some others still do not care about these procedures. Reaction to pandemics may vary related to the health concern of each person. Health concerns and anxiety associated with epidemics/pandemics can have a significant psychological impact (e.g., stress, negative intrusive thoughts, avoidance), can be related to ineffective preventive behavior. That have adverse longer-term consequences such as persistent pessimism (C. Wang et al., 2020).

Hope theory must be suitable for use in the context of this study. Even so, high expectations do not always mean someone will engage in behaviors that improve health behaviors. This behavior must be adopted as a goal. One way to measure whether people adopt goals is to ask about the personal interests of those goals. According to Hope Theory (Snyder, 2002), when people consider an important goal, expectations must predict success in achieving that goal. In this study, we assess the perceived importance of various health promotion goals (eg to eat healthy foods, to exercise more). The level of hope must interact with the importance level for predict health-related behavior, with individuals of higher hope achieving important personal goals more easily than individuals of lower hope.

The authors investigated whether the perceived risk is associated with adolescence' decision-making in health behaviours. In the current paper, perceived life chance was chosen for two reasons, 1) earlier studies indicating that the "nothing to lose" attitudes were contributing to high-risk healthy behaviours among adolescents. However, those studies did not inform whether the regular, everyday health-related behaviours associated with the risk-healthy behaviour. 2) The socio-economic context may associate with the variance of the perceived risk level. Social-demographic variables, such as income, education background, and occupation are used to identified one's social position in the society (Lynch \& Kaplan, 2000). Measures of perceived life changes provide the researcher's chance to understand this phenomenon as experienced by the individual. This measure also provides a piece of information if the evaluation of subjective expectation for the future is motivational about health behaviours. This assumption builds upon earlier studies about factors that are associated with adolescences' future expectations.(Dominitz et al., 2001; Fischhoff et al., 2000).

\section{METHODOLOGY}

\section{Participant}

The researchers were collecting the data using an online survey. Four hundred thirty-one psychology college students across the university in Indonesia have participated in the study. The sample characteristic was female (79.5\%). With an average age of $20.79(\mathrm{SD}=2.28)$.

\section{Measures}

Question-wording means, and standard deviations are presented in Table 1. All variables were measured using Likerttype scales. The authors used the hope instruments (Bults et al., 2011) that were previously used for the study about the N1h1influenza virus.

\section{Perceived risk}

Perceived risk scale was used to measure participant's perception of risk (Bults et al., 2011) this scale consists of eight items covering three dimensions of risk; the first three items aim to measure perceived severity (Chronbach alpha 0.8), and another three items for measure vulnerability (Crombach alpha 0.6), and the last two items for perceived anxiety (Cronbach alpha 0.8).

\section{Knowledge of Health}

Most studies on health knowledge are disease-specific, and measurement tools are usually questionnaires specific to the purpose of the survey or the study population. Most researchers would use questionnaires related to their area of research that has already been published and validated. If none exists, reliability and validity testing can use with new questionnaires and scales (Artino et al., 2014; Edwards, 2010). Therefore, the knowledge about the pandemic was measured using five items taken from the health knowledge general survey (Bults et al., 2011).

\section{Hope}

Hope was measured using two items ("Dari data yang ada maka akan terjadi penurunan penularan; "Kami dapat kembali hidup normal tanpa takut dalam waktu). The answer based on respondent's range of time $(1=$ less than 1 
month; $2 ; 1-3$ month; 3= 3- 6 month; $4=6-12$ month; 5= more than 1 years). The maximum score for knowledge is five, and it is classified into two categories with high knowledge scores above mean and low knowledge scores below mean. Hope scale assesses pathways and agencies regarding goals in general. Hope has been found to strongly predicted academic performance, athletic performance, depression, anxiety, and meaning in life (Snyder et al., 2002). The previous study has shown excellent retest reliability for the Hope Scale for dispositional construct (Snyder et al., 1991).

Table 1: Questionnaire Items, Means, and Standard Deviations.

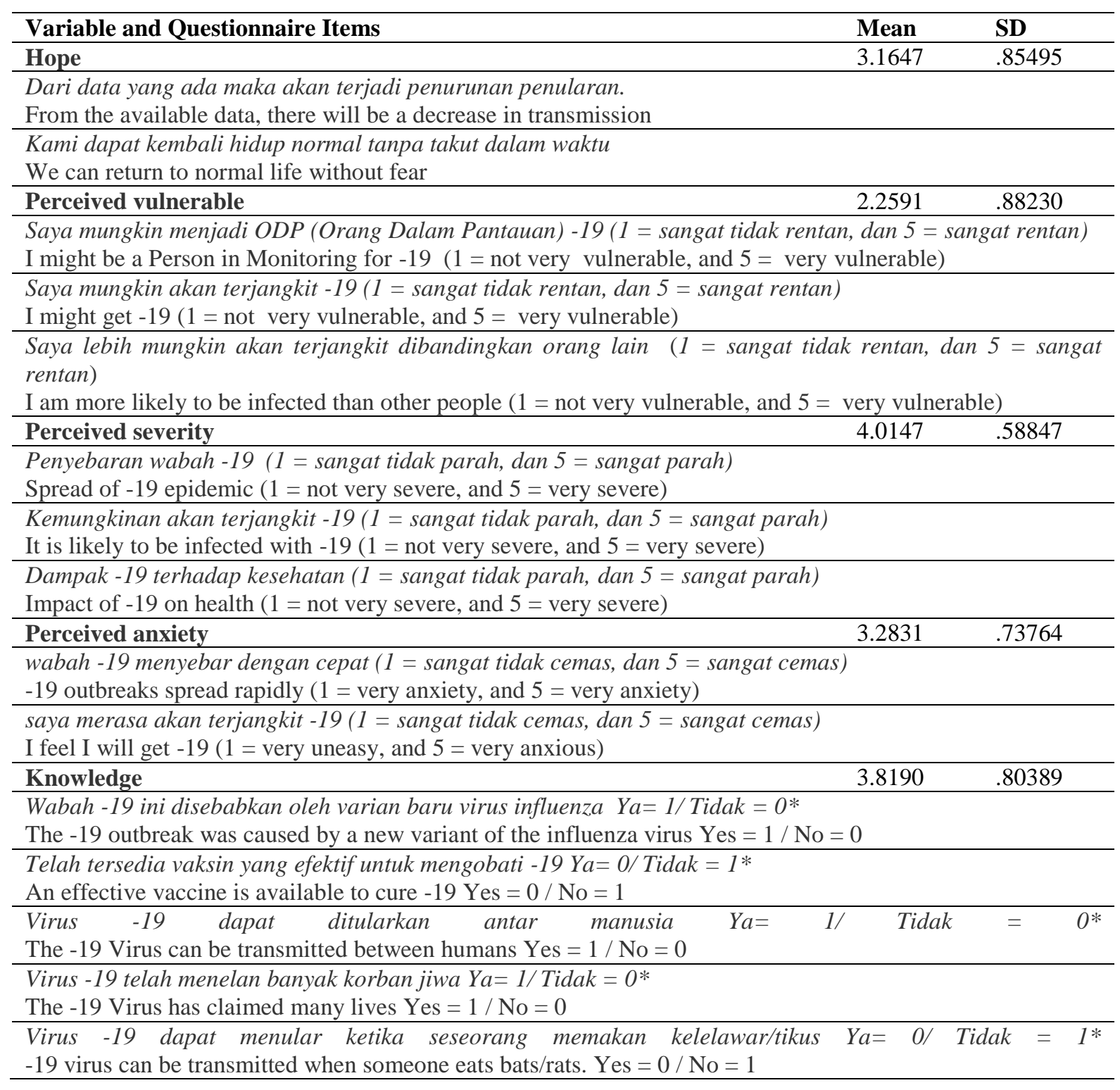

*Italics for Indonesia language

\section{Statistical Analysis}

This study employed three statistical analyses. First, we computed descriptive statistics for all variables. In the second analysis, a correlation matrix using Pearson's product-moment coefficient was presented. In the third analysis, a multiple regression analysis aims to examine the contribution of perceived risk and knowledge on hope was provided. Result of descriptive analysis shows female students have a higher level of hope $(\mathrm{M}=79.35$; $\mathrm{SD}=7.48)$ and perceived risk $(\mathrm{M}=$ 51.27; $\mathrm{SD}=5.03)$ compared to male students hope $(\mathrm{M}=71.40 ; \mathrm{SD}=10.51)$ and perceived risk $(\mathrm{M}=43.49, \mathrm{SD}=4.88)$. Both genders showed a medium-low level of Knowledge (female: $\mathrm{M}=24.20, \mathrm{SD}=3.41$; male: $\mathrm{M}=23.63, \mathrm{SD}=4.52$ ) (see Table II).

Table 2: Mean and Standard Deviation by gender

\begin{tabular}{lllll}
\hline Measures & Gender & $\mathbf{N}$ & Mean & Standard Deviation \\
\hline Hope & Female & 343 & 3.1968 & .85150 \\
\cline { 2 - 5 } & male & 88 & 3.0398 & .86177 \\
\hline Knowledge & Female & 343 & 3.8484 &. .80951 \\
\hline
\end{tabular}




\begin{tabular}{llllll}
\hline & & male & 88 & 3.7045 & .77547 \\
\hline \multirow{2}{*}{ Perceived Risk } & Perceived severity & Female & 343 & 4.0476 & .58183 \\
\cline { 2 - 5 } & & male & 88 & 3.8864 & .59989 \\
\cline { 2 - 5 } & Perceived Vulnerability & Female & 343 & 2.2187 & .86994 \\
\cline { 2 - 5 } & male & 88 & 2.4167 & .91706 \\
\cline { 2 - 5 } & Perceived Anxiety & Female & 343 & 3.3090 & .73298 \\
\cline { 2 - 5 } & male & 88 & 3.1818 & .75117 \\
\hline
\end{tabular}

\section{RESULTS AND DISCUSSION}

Table 3 below indicates correlations among our key variables. There was a significant negative correlation between hope based on perceived risk and knowledge. While perceived anxiety did not significantly correlate with other independence variables. Most of the correlation coefficients, not more than 0.2 are negatively correlated. Only perceived anxiety that did not sign in the level of sign 0.5 , we argue that it is reasonable given that hope to have a negative correlation with knowledge (-.0.88), perceived severity (-0.65), and vulnerability(-0.157). Even anxiety has a negative correlation (-.190) but not significant with hope. This result implies that hope and knowledge have a significant correlation with perceived severity and perceived vulnerability correlated at $(0,437)$.

Table 3: Correlation matrix of the primary variable

\begin{tabular}{llllll}
\hline Variable & Hope & Knowledge & $\begin{array}{l}\text { Perceived } \\
\text { severity }\end{array}$ & $\begin{array}{l}\text { Perceived } \\
\text { Vulnerability }\end{array}$ & Perceived Anxiety \\
\hline Hope & 1.000 & -.088 & -.065 & -.157 & -.190 \\
\cline { 2 - 6 } & & $.033^{*}$ & $.000^{*}$ & $.001^{*}$ & .089 \\
\hline Knowledge & -.088 & 1.000 & .069 & .041 & .056 \\
\cline { 2 - 5 } & $.033^{*}$ & & .12 .1 & .197 & .077 \\
\hline Perceived severity & -.065 & .069 & 1.000 & .437 & .306 \\
\cline { 2 - 5 } & .000 & .12 .1 & & $.000^{*}$ & $.000^{*}$ \\
\hline Perceived Vulnerability & -.157 & .041 & .437 & 1.000 & .185 \\
\cline { 2 - 5 } & $.001^{*}$ & .197 & $.000^{*}$ & & $.000^{*}$ \\
\hline Perceived Anxiety & -.190 & .056 & .306 & .185 & 1.000 \\
\cline { 2 - 5 } & & .077 & $.000^{*}$ & $.000^{*}$ & \\
\hline
\end{tabular}

* Sig. (1-tailed) $N=431$

As shown in this study results, hope on pandemic was significantly affected by perceived severity, perceived vulnerability, and knowledge. A literature review assessing factors that influence preventive behaviour during pandemic situations highlighted that perceived susceptibility to and severity of the disease as well as believing in the effectiveness of protective measures increased its implementation (Bish et al., 2011).

The relationship between risk perception, hope, and knowledge is the interest to many health researchers. Community members often misinterpret the risks of their health problems (violating the accuracy hypothesis) and correct this misinterpretation seen (due to researchers' trust in behavioral motivation hypotheses) as a way to encourage healthy behavior. As we have shown, this study is completely different and may even have the opposite sign (Weinstein \& Nicolich, 1993; Weinstein et al., 1998). In this study, the result will lead researchers to conclude that a high perception of the risk of preventing from -19 and making an explanation for this finding, might suggest that people who feel risky to continue risky behavior in a vain attempt to convince themselves that they are not really at risky.

Table 4: The Anova results of the effect of all independent variables on dependent variables

\begin{tabular}{lllllll}
\hline Model & Sum of Squares & df & Mean Square & F & Sig. \\
\hline \multirow{2}{*}{1} & Regression & 18.755 & 4 & 4.689 & 6.758 & $.000^{\mathrm{b}}$ \\
\cline { 2 - 7 } & Residual & 295.549 & 426 & .694 & & \\
\cline { 2 - 7 } & Total & 314.304 & 430 & & & \\
\hline
\end{tabular}

a. Dependent Variable: Hope.

b. Predictors: (Constant), knowledge, perceived severity, Perceived Vulnerable, Perceived anxiety.

As seen in Table 4 above, the significance value of the $\mathrm{F}$ test is 0.000 where the significance level is $5 \%$ or 0.05 , which means that there is a significant association between the overall model consisting knowledge and perceived risk to hope in dealing with pandemics among college students in Indonesia. 
Table 5: Regression Model Coefficient

\begin{tabular}{|c|c|c|c|c|c|c|}
\hline \multirow{2}{*}{\multicolumn{2}{|c|}{ Model }} & \multicolumn{2}{|c|}{ Unstandardized Coefficients } & \multirow{2}{*}{$\begin{array}{l}\text { Standardized Coefficients } \\
\text { Beta }\end{array}$} & \multirow[t]{2}{*}{$\mathbf{t}$} & \multirow[t]{2}{*}{ Sig. } \\
\hline & & $\mathbf{B}$ & Std.Error & & & \\
\hline 1 & (Constant) & 4.605 & .340 & & 13.530 & .000 \\
\hline & Knowledge & -.081 & .050 & -.077 & -1.623 & .105 \\
\hline & Perceived anxiety & .068 & .063 & .059 & 1.083 & .279 \\
\hline & Perceived Vulnerable & -.142 & .051 & -.147 & -2.801 & .005 \\
\hline & Perceived Severity & -.257 & .072 & -.177 & -3.576 & .000 \\
\hline
\end{tabular}

a. Dependent Variable: Hope

As seen on the Table 5, the regression equation can be seen as follows: Hope $=4,605+(-0.81)$ Knowledge +0.68 perceived anxiety $+(-0.142)$ perceived vulnerable * $+(-0.257)$ Perceived severity * (*significant at 0.05$)$. it can be concluded that only perceived vulnerability and perceived severity that have significant influences on the dependent variable (hope).

Further, it can be also seen that are two independent variables have a significant influence on hope. This study also wants to find out the amount of contribution from each independent variable influences hope in a pandemic, then ranks it from the largest to the smallest load. Based on the data in table 2, it can be seen that the sequence of predictors that have contributed to the hope in a pandemic from the largest to the smallest is Perceived vulnerable with a contribution of $14 \%$ and perceived severity with a contribution of $-17 \%$.

\section{CONCLUSION}

The purpose of this study was to examine the risk perception consist of perceived vulnerability, severity, and anxiety to the -19 Virus based on hope and knowledge about health in the pandemic. This study reveals risk perceptions predispose college students to pandemic health knowledge. This study also suggests that perceived risk and knowledge added significantly to the model explaining the variance of hope. In addition, this study's findings may inform students' knowledge so that they might optimize students' college to minimize the risk -19 with health knowledge.

In conclusion, we were able to demonstrate that the hope and knowledge took place when risk perception related to the disease was low, while scepticism and misconceptions about the pandemic and exposure from media how to live healthy to anticipate being infected by the coronavirus were frequent. These findings are in line with surveys of other countries conducted during the pandemic (Bish et al., 2011; Nguyen et al., 2011) Rebuilding trust in recommendations of public health authorities and addressing common misinformation in a pandemic will be a challenge when preparing for a future pandemic. The pre-pandemic development of tailormade information strategies accompanied by surveys to monitor public perception implemented early in the pandemic should be considered for future pandemic preparedness planning and the mitigation of health threats on the college student level.

\section{LIMITATION AND STUDY FORWARD}

A number of limitations in this study were identified. First, it may contain topics not related to this study and therefore may have reduced potential biases in our conclusions. Second, our survey results are then weighted to control for possible selection bias. Self-selection bias is another major limitation of online survey research (Witmer et al., 1999). (Thompson et al., 2003) Finally, the sample may not fully cover the entire population characteristic in Indonesia. This sampling problem impedes the ability of researchers to make generalizations about study findings.

\section{ACKNOWLEDGEMENT}

We are grateful for the Institution for Research, and Community Services Universitas Negeri Jakarta was supporting this research through the research grant. No. 26/KOMP-UNJ/LPPM/V/2020, Mei, $4^{\text {th }} 2020$

\section{AUTHORS CONTRIBUTION}

All authors participated in the planning and designing of the study and the online survey. GG and HM coordinated the research and took overall responsibility for the delivery of the work and data analysis. GIR had responsibility for data collection. All authors approved the final manuscript as submitted and agree to be accountable for all aspects of the work.

\section{REFERENCES}

1. Artino, A. R., la Rochelle, J. S., Dezee, K. J., \& Gehlbach, H. (2014). Developing questionnaires for educational research: AMEE Guide No. 87. Medical Teacher, 36(6), $463-474$. https://doi.org/10.3109/0142159X.2014.889814

2. Barr, R. G., Celli, B. R., Mannino, D. M., Petty, T., Rennard, S. I., Sciurba, F. C., Stoller, J. K., Thomashow, B. M., \& Turino, G. M. (2009). Comorbidities, Patient Knowledge, and Disease Management in a National Sample of Patients with COPD. American Journal of Medicine, 122(4), 348-355. https://doi.org/10.1016/j.amjmed.2008.09.042 
3. Bish, A., Yardley, L., Nicoll, A., \& Michie, S. (2011). Factors associated with uptake of vaccination against pandemic influenza: A systematic review. In Vaccine (Vol. 29, Issue 38, pp. 6472-6484). https://doi.org/10.1016/j.vaccine.2011.06.107

4. Brewer, N. T., Weinstein, N. D., Cuite, C. L., \& Herrington, J. E. (2004). Risk Perceptions and Their Relation to Risk Behavior. Annals of Behavioral Medicine, 27(2), 125-130. https://doi.org/10.1207/s15324796abm2702_7

5. Bults, M., Beaujean, D. J., de Zwart, O., Kok, G., van Empelen, P., van Steenbergen, J. E., Richardus, J. H., \& Voeten, H. A. (2011). Perceived risk, anxiety, and behavioural responses of the general public during the early phase of the Influenza A (H1N1) pandemic in the Netherlands: results of three consecutive online surveys. BMC Public Health, 11(1), 2. https://doi.org/10.1186/1471-2458-11-2

6. Cao, W., Fang, Z., Hou, G., Han, M., Xu, X., Dong, J., \& Zheng, J. (2020). The psychological impact of the -19 epidemic on college students in China. Psychiatry Research, 287. https://doi.org/10.1016/i.psychres.2020.112934

7. Cardwell, J., Health, W. C.-U., 1981, undefined, Travis, L. B., Curtis, R. E., Glimelius, B., Holowaty, E., Leeuwen, F. E. van, Lynch, C. F., Adami, J., Gospodarowicz, M., Wacholder, S., Inskip, P., \& Denniston, R. W. (1993). Second cancers among long-term survivors of non-Hodgkin's lymphoma. JNCI: Journal of the National Cancer Institute, 85(23), 225.

8. Carey, M., \& .E.E. Schroder. (2002). Development and psychometric evaluation of the patient's HIV knowledge questionnaire (PHKQ). AIDS Education and Prevention, 14(2), $172-182$. https://doi.org/10.1007/s11096-020-00963-Z

9. Cheavens, J. S., Feldman, D. B., Woodward, J. T., \& Snyder, C. R. (2007). Hope in Cognitive Psychotherapies: On Working With Client Strengths. Journal of Cognitive Psychotherapy, 20(2), 135-145. https://doi.org/10.1891/088983906780639844

10. Chen, L. S., \& Kaphingst, K. A. (2011). Risk perceptions and family history of lung cancer: differences by smoking status. Public Health Genomics, 14(1), 26-34.

11. Chen, Q., Liang, M., Li, Y., Guo, J., Fei, D., Wang, L., He, L., Sheng, C., Cai, Y., \& Li, X. (2020). Mental health care for medical staff in China during the -19 outbreak. The Lancet Psychiatry, 7(4), e15-e16.

12. Denniston, R. W. (1981). Cancer knowledge, attitudes, and practices among black Americans. Progress in Clinical and Biological Research, 53, 225-235. https://www.ncbi.nlm.nih.gov/pubmed/7465589

13. Dominitz, J., Manski, C. F., \& Fischhoff, B. (2001). Who are youth "at risk"? Expectations evidence in the NLSY97. In Social awakening: Adolescent behavior as adulthood approaches. (pp. 230-257). Russell Sage Foundation.

14. Duan, L., \& Zhu, G. (2020). Psychological interventions for people affected by the -19 epidemic. The Lancet Psychiatry, 7(4), 300-302.

15. Edwards, P. (2010). Questionnaires in clinical trials: Guidelines for optimal design and administration. In Trials (Vol. 11). https://doi.org/10.1186/1745-6215-11-2

16. Ferrer, R., \& Klein, W. M. (2015). Risk perceptions and health behavior HHS Public Access. Current Opinion in Psychology, 5, 85-89. https://doi.org/10.1016/j.copsyc.2015.03.012

17. Fischhoff, B., Parker, A. M., de Bruin, W. B., Downs, J., Palmgren, C., Dawes, R., \& Manski, C. F. (2000). Teen expectations for significant life events. The Public Opinion Quarterly, 64(2), 189-205.

18. Gilman, R., Dooley, J., \& Florell, D. (2006). Relative levels of hope and their relationship with academic and psychological indicators among adolescents. Journal of Social and Clinical Psychology, 25(2), 166-178. https://doi.org/10.1521/jscp.2006.25.2.166

19. Grueninger, U. J. (1995). Arterial hypertension: lessons from patient education. Patient Education and Counseling, 26(1-3), 37-55. https://doi.org/10.1016/0738-3991(95)00750-T

20. Hansen, H., Pohontsch, N., van den Bussche, H., Scherer, M., \& Schäfer, I. (2015). Reasons for disagreement regarding illnesses between older patients with multimorbidity and their GPs - A qualitative study. BMC Family Practice, 16(1), 68. https://doi.org/10.1186/s12875-015-0286-X

21. Jones, D., Cook, R., Rodriguez, A., \& Waldrop-Valverde, D. (2013). Personal HIV knowledge, appointment adherence and HIV outcomes. AIDS and Behavior, 17(1), 242-249. https://doi.org/10.1007/s10461-012-0367-y

22. Kahneman, D. (1973). Attention and effort (Vol. 1063). Prentice-Hall series in experimental psychology.

23. Kalichman, S. C., Pope, H., White, D., Cherry, C., Amaral, C. M., Swetzes, C., Flanagan, J., \& Kalichman, M. O. (n.d.). Association Between Health Literacy and HIV Treatment Adherence: Further Evidence from Objectively Measured Medication Adherence. https://doi.org/10.1177/1545109708328130

24. Keller, P. A., Lipkus, I. M., \& Rimer, B. K. (2002). Depressive Realism and Health Risk Accuracy: The Negative Consequences of Positive Mood. Journal of Consumer Research, 29(1), 57-69. https://doi.org/10.1086/339921

25. Lerner, J. S., \& Keltner, D. (2000). Beyond valence: Toward a model of emotion-specific influences on judgement and choice. Cognition \& Emotion, 14(4), 473-493. https://doi.org/10.1080/026999300402763

26. Li, Z., Ge, J., Yang, M., Feng, J., Qiao, M., Jiang, R., Bi, J., Zhan, G., Xu, X., Wang, L., Zhou, Q., Zhou, C., Pan, Y., Liu, S., Zhang, H., Yang, J., Zhu, B., Hu, Y., Hashimoto, K., .. Yang, C. (2020). Vicarious 
traumatization in the general public, members, and non-members of medical teams aiding in -19 control. Brain, Behavior, and Immunity. https://doi.org/10.1016/j.bbi.2020.03.007

27. Lopez, S. J., Snyder, C. R., \& Pedrotti, J. T. (2004). Hope: Many definitions, many measures. In Positive psychological assessment: A handbook of models and measures. (pp. 91-106). American Psychological Association. https://doi.org/10.1037/10612-006

28. Lynch, J., \& Kaplan, G. (2000). Socioeconomic position (Vol. 2000). Social epidemiology. New York: Oxford University Press.

29. Marques, S. C., Pais-Ribeiro, J. L., \& Lopez, S. J. (2009). Validation of a Portuguese version of the children's hope scale. School Psychology International, 30(5), 538-551. https://doi.org/10.1177/0143034309107069

30. Mathur, S., \& Levy, M. (2013). Lung cancer risk perception and distress: Difference by smoking status, and role of physical activity and race among us population. Epidemiology Biostatistics and Public Health, 10(2), 111. https://doi.org/10.2427/8839

31. Mills, B., Reyna, V. F., \& Estrada, S. (2008). Explaining contradictory relations between risk perception and risk taking. Psychological Science, 19(5), 429-433. https://doi.org/10.1111/j.1467-9280.2008.02104.x

32. Nguyen, T., Henningsen, K. H., Brehaut, J. C., Hoe, E., \& Wilson, K. (2011). Acceptance of a pandemic influenza vaccine: A systematic review of surveys of the general public. In Infection and Drug Resistance (Vol. 4, Issue 1, pp. 197-207). https://doi.org/10.2147/IDR.S23174

33. Onwuegbuzie, A. J., \& Daley, C. E. (1999). Relation of hope to self-perception. Perceptual and Motor Skills, 88(2), 535-540. https://doi.org/10.2466/pms.1999.88.2.535

34. Ownby, R. L., Waldrop-Valverde, D., Hardigan, P., Caballero, J., Jacobs, R., \& Acevedo, A. (2013). Development and Validation of a Brief Computer-Administered HIV-Related Health Literacy Scale (HIV-HL). AIDS and Behavior, 17(2), 710-718. https://doi.org/10.1007/s10461-012-0301-3

35. Rosenstock, I. M., Strecher, V. J., \& Becker, M. H. (1994). The health belief model and HIV risk behavior change. In Preventing AIDS (pp. 5-24). Springer.

36. Sarafino, E. P. (2008). Health biopsychosocial interactions . New York: John Willey\& Sons. Inc.

37. Selden, C. R., Zorn, M., Ratzan, S. C., \& Parker, R. M. (2000). Health literacy. Current Bibliographies in Medicine, 1, 2000.

38. Shepperd, J. A., Findley-Klein, C., Kwavnick, K. D., Walker, D., \& Perez, S. (2000). Bracing for loss. Journal of Personality and Social Psychology, 78(4), 620-634. https://doi.org/10.1037/0022-3514.78.4.620

39. Slovic, P. (1987). Risk Perception. Science, 236(4799), 280-285.

40. Snyder, C. R. (2002). Hope theory: Rainbows in the mind. Psychological Inquiry, 13(4), $249-275$. https://doi.org/10.1207/S15327965PLI1304_01

41. Snyder, C. R., Harris, C., Anderson, J. R., Holleran, S. A., \& et al. (1991). The will and the ways: Development and validation of an individual-differences measure of hope. Journal of Personality and Social Psychology, 60(4), 570-585. https://doi.org/10.1037//0022-3514.60.4.570

42. Taylor, S. (2019). The Psychology of Pandemics: Preparing for the Next Global Outbreak of Infectious Disease. Cambridge Scholars Publishing.

43. Thompson, L. F., Surface, E. A., Martin, D. L., \& Sanders, M. G. (2003). From paper to pixels: Moving personnel surveys to the Web. In Personnel Psychology (Vol. 56, Issue 1, pp. 197-227). Personnel Psychology, Inc. https://doi.org/10.1111/j.1744-6570.2003.tb00149.X

44. Volk, M. L., Fisher, N., \& Fontana, R. J. (2013). Patient knowledge about disease self-management in cirrhosis. American Journal of Gastroenterology, 108(3), 302-305. https://doi.org/10.1038/ajg.2012.214

45. Wang, C., Pan, R., Wan, X., Tan, Y., Xu, L., Ho, C. S., \& Ho, R. C. (2020). Immediate psychological responses and associated factors during the initial stage of the 2019 coronavirus disease (-19) epidemic among the general population in China. International Journal of Environmental Research and Public Health, 17(5). https://doi.org/10.3390/ijerph17051729

46. Wang, Q., Hay, M., Clarke, D., \& Menahem, S. (2014). Associations between knowledge of disease, depression and anxiety, social support, sense of coherence and optimism with health-related quality of life in an ambulatory sample of adolescents with heart disease. Cardiology in the Young, 24(1), 126-133. https://doi.org/10.1017/S1047951113000012

47. Weinstein, N. D., \& Nicolich, M. (1993). Correct and incorrect interpretations of correlations between risk perceptions and risk behaviors. Health Psychology, 12(3), 235.

48. Weinstein, N. D., Rothman, A. J., \& Nicolich, M. (1998). Use of correlational data to examine the effects of risk perceptions on precautionary behavior. Psychology and Health, 13(3), 479-501.

49. Wheaton, M. G., Abramowitz, J. S., Berman, N. C., Fabricant, L. E., \& Olatunji, B. O. (2012). Psychological predictors of anxiety in response to the H1N1 (swine flu) pandemic. Cognitive Therapy and Research, 36(3), 210-218. https://doi.org/10.1007/s10608-011-9353-3

50. Witmer, D., Coleman, R., \& Katzman, S. (1999). From paper-and-pencil to screen-andkeyboard. Doing internet research: critical issues and methods for examining the net. S. Jones. Thousand Oaks, CA, Sage.

51. Yang, Y., Peng, F., Wang, R., Guan, K., Jiang, T., Xu, G., Sun, J., \& Chang, C. (2020). The deadly coronaviruses: The 2003 SARS pandemic and the 2020 novel coronavirus epidemic in China. Journal of Autoimmunity, 109. https://doi.org/10.1016/j.jaut.2020.102434 